\title{
SYSTEM-TRANSDISCIPLINARY PARADIGM IMPLICATION TO SOLVE CRISISOLOGY PROBLEMS EADINGS ${ }^{1}$
}

\author{
Author(s) / Auteur(s) : \\ Mikhail MOKIY \\ DSc in Economics, Professor \\ State University of Management, Moscow; Russia University, \\ Russian Presidential Academy of National Economy and Public Administration \\ mokiy2000@yandex.ru
}

\begin{abstract}
Résumé :
The article presents the results of applying the system-transdisciplinary paradigm to solve the problems of modern crisisology. One way to solve complex problems is to change the scientific paradigm. The paradigm shift involves a change in perspective. As a result, it becomes possible to create a fundamentally different interpretation of the known facts, as well as the formulation of problems and ways to solve them.

The article shows how the use of the system-transdisciplinary paradigm allows to change the understanding of the causes of crises, theoretically substantiate the methodological principles of calculating the timing of their occurrence, as well as to outline measures to prevent their negative manifestations.

Within the framework of this paradigm, the system is an order that determines the unity and integrity of elements and interrelations between them. Its existence allowed to build models describing this order in informational, temporal and spatial aspects.

Adaptation of these models to the study of economic processes and phenomena made it possible to theoretically substantiate a number of laws, which are revealed experimentally. This applies to the duration of the global crisis, the time of onset and characteristics of symptoms in different countries. The theoretical substantiation of features of manifestation of crises is offered. Operating with the assumption that the cause of the crisis is the manifestation of this order, a retrospective analysis of the development of the world economy from 1792 was conducted, along with a forecast of crises. The results of the 20-year-long test projections allow to speak about high explanatory and predictive powers of this methodological approach. The article presents the results of verification of these provisions.

Special attention in the paper is given to what is revealed with the help of this approach, patterns are universal. Therefore, its application sets a new vector in the formulation, ranking and solution of the identified problems of objects that can be viewed as a system.
\end{abstract}

Keywords / Mots-clés :

crisisology, systemic transdisciplinary paradigm, model order, prediction, economic development bstract text

\section{INTRODUCTION FUNDAMENTALS OF SYSTEM-TRANSDISCIPLINARY PARADIGM}

As it is known, the economic crisis is commonly believed to be a negative phenomena in the economy. The result of the crisis is a decline in the living standard of the population and a decrease of the real gross national product.

The history of economic development over the past two centuries has provided with an opportunity to assure that this phenomena has a different periodicity and depth, and is appropriate for different types of economies. And in the modern world economy, wherein the majority of states are interrelated and interdependent, this phenomena has acquired a global disposition.

Every new crisis causes a wave of actions explaining the reasons of a particular crisis. There are explanations for what was done wrong, and the measures to prevent the mistakes repetition are being taken. But.... every time a new crisis occurs suddenly and proceeds anew.

\footnotetext{
${ }^{1}$ The research was carried out at the expense of a grant from the Russian Foundation for Basic Research (project No. 18-01000217).
} 
There is quite a lot of actions dedicated to economic dynamics, sustainable development problems, etc. Despite this, some totality of theoretical provisions on the nature of crises has been developed. The mere listing of the names of authors and points of view on the problems of crises can fill out more than one page. But with all the multiplicity of points of view, the majority of economists agree that crises are associated with the economic development circularity.

There are quite a large number of works devoted to crises, economic dynamics, problems of sustainable development, etc. The task of our article does not include a comparative analysis of works devoted to the causes of crises. Just listing the names of authors and points of view on the problems of crises can take more than one page. But with all the multiplicity of points of view, most economists agree that crises are associated with the cyclical nature of economic development. Therefore, a certain mass of hypotheses and theoretical concepts has developed for solving the main problems of crisisology, which can be designated as follows:

- What causes crises occurrence?

- Is it possible to predict the crisis calendar period?

- Why every crisis differs from the previous one?

- Why the crisis shows up differently in various countries?

- How to prevent crises?

Obviously, these are not all the problems of Crisisology, but, from our point of view, these are fundamental problems. And as yet there is no satisfactory theoretical concept that would allow to solve these problems. Our congress is a confirmation of this fact. This is a normal situation in science, especially in such a young as crisisology. However, the situation is complicated by the fact that the confirmation of theoretical concepts in economic dynamics is a very difficult problem associated with the inability to put experience or experiment, and the actual confirmation of theoretical assumptions need to wait many years and decades. Therefore, it is necessary to change approaches to the study of such complex objects and problems.

One of the ways for solving complex problems is to change the scientific paradigm (Kuhn T., 1975). Despite the fact that Thomas Kuhn did not give an unambiguous definition of the term "paradigm", he described a paradigm matrix that includes three types of elements:

- ontological interpretations of the object;

- symbolic generalizations or laws;

- samples of problems solutions.

At the heart of any ontology is always a world outlook. Change in ontological interpretation is possible as a result of a change in world outlook. As a result, the possibility of a crucially different interpretation of known facts, of a different problems and of the determination of their solution vector emerges. One example of this is meant to be the change of the geocentric world outlook to the heliocentric one. As a result, the cause of sunrise and sunset began to be treated differently.

The directions of the systemic and transdisciplinary approach, which emerged at the end of the 20th century, formed a new world outlook allowing a new interpretation of economic development and, in particular, solve the problems of crisis science. Let us consider the matrix of the systemtransdisciplinary paradigm and its application to solving the problems we have identified 


\section{FUNDAMENTALS OF SYSTEM-TRANSDISCIPLINARY PARADIGM}

The system-transdisciplinary paradigm is based on the synthesis of two ideological concepts - holism and unicentrism (Mokiy V.S., Lukyanova T.A, 2017). The World exists because there is an order in it that determines its integrity and unity. All the objects discovered and not yet discovered by us and the connections between them are fragments of the World. The purpose of any fragment is to transform substance and energy to ensure the unity and integrity of the World. The implementation of this function leads to the emergence of the needs for each element-fragment of the World and the emergence of the process of exchange of matter and energy to satisfy them. To do this, the fragments must enter into numerous and diverse connections with other fragments, creating vertical and horizontal ensembles of elements. The order particularly determines the unity of the elements, allows to determine the place, sense and meaning of each element, to reveal the interrelations between the elements. To this extent, order determines the unity of the world. Moreover, order provides the conditions for the appearance, existence and development of elements and the emergence of interrelations. Manifesting in time and space, objects - fragments and connections between them are actualized in reality. The postulation of a unified order predetermines the identity of the order of each element-fragment development. Otherwise, their interaction, communication will be impossible. It means that order should have the identity of forms for fragments and the World as a whole - an isomorphism. From this worldview position, the system is an order that determines the unity and integrity of elements and interrelations between them.

From this standpoint, the ontological interpretation of economic relations is as follows.

\section{Ontological interpretation of the object}

Mankind is a fragment of the planetary system. The function of the planetary substance and energy transforming is inherent in each person immanently, though only because we breath. But we still need to drink, eat, dress and live somewhere. As a result, people who at their level realize the process of the planetary substance and energy transformation, have needs. To meet the needs, people are forced to establish links between themselves (from the family to humanity in whole) and other fragments of the planet, in order to create, share and distribute wealth. A phenomenon called by people "socioeconomic relations" emerges. These relations are an indispensable attribute of the development of mankind, as the implementation of the process of planetary substance and energy transformation.

Therefore, these relations must develop in accordance with the laws that practice in the World and on the regard of all other World fragments. In case these laws are violated, nature will have to adjust the mankind evolution. Herewith, such laws should have the identity of forms for fragments and the world entirely (legislative isomorphism). Otherwise, communication between fragments is impossible. Within this framework, these laws of nature have a universal or transdisciplinary disposition.

Misunderstanding or ignoring this fact generates "chimeras of desire" among people. As a result, decisions in the field of socially-economic relations are made on the basis of a desire (albeit very good and disinterested) to see these relations as such. However, as it is known, ignorance of the law is no excuse for its violation.

What are these laws?

\section{Symbolic generalizations and laws}

The order isomorphism described above allowed to use the so-called order units as a methodological tool for research. Such are the information, temporal (temporal) and spatial units of order. Here it is necessary to explain that the term "information" is interpreted by us as a state of potency in all its varieties. The term "unit of order" is understood to mean a logically completed arrangement and a harmonious combination of space fragments, signs of information and time periods in the system.

The basis for constructing units of order is the so-called parametric information dipole encapsulating a unity of quantitative and qualitative information (figure1).

- Information of a quantitative type is a form of manifestation of the potency of a medium (object) characterizing this state from the perspective of magnitude. 
- Information of a qualitative type is a form of manifestation of the potency of a medium (object) characterizing this state from the perspective of essential properties and functions.

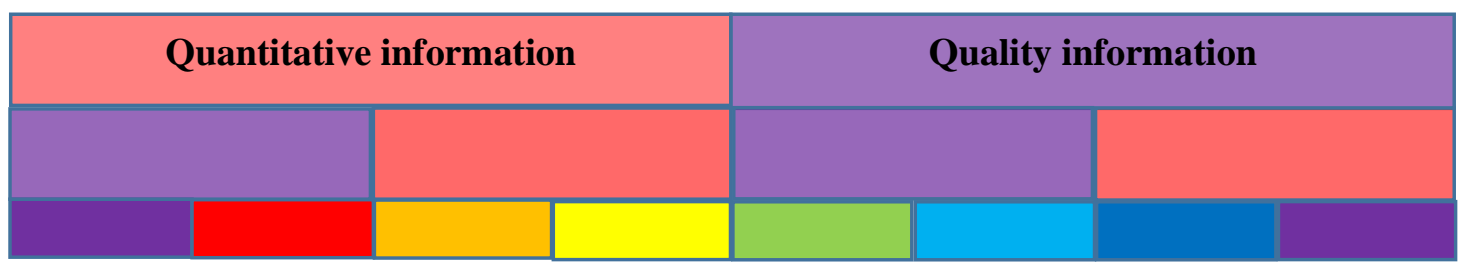

Figure.1. Model of information unit of the order

The potency of the system transformation is possible only with its unity and integrity, that the purpose of a single ordered environment is the preservation of self-unity. This goal predetermines the preservation of a balance between the quantitative and qualitative state of the environment in each period of its development and in each of its spatial fragments (figure 2). However, each fragment of a single ordered environment has an individual norm or a balance between its quantitative and qualitative state (between quantitative and qualitative information). So, for example, if it is cold in Antarctica for the whole year - it is the norm.

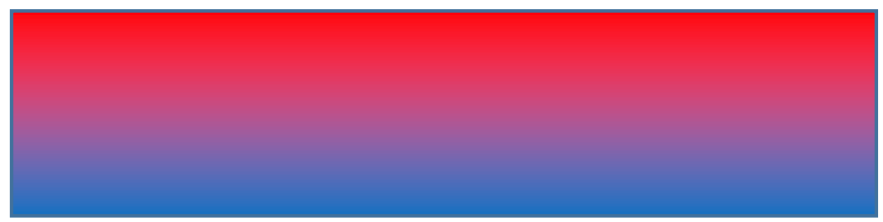

Figure. 2. Information balance

If by we mean by development ${ }^{2}$ the process of transition from one qualitative state to another one, then the process of development can be divided into periods during which a complete transformation of the state of the object occurs. In accordance with the regularities of the information unit of the order, the process of disclosing the potency in time is represented as a set of waves or a multiplex (figure 3 ). Multiplex waves or M-waves - unlike their physical analogue - mean not the amplitude of the oscillation but the calendar duration of the periods in which development processes occur under the auspices of either quantitative or qualitative object transformations. Each wave represents the time interval during which the potency transformation occurs due to the information characteristic. The potency transformation of potency in this interval acquires a phase meaning and a phase goal. The successive change in the activity of the quantitative and qualitative periods determines the cyclical nature of the process of any development - the seasonal change, respiration, frying eggs or writing this article.

\footnotetext{
2 The process is a successive change of states, stages of development

Period is the time interval during which something happens;

Phase is a separate moment, a stage in the development of some process;

Cycle is a set of phenomena, processes that makes up a circuit for a certain time interval.
} 


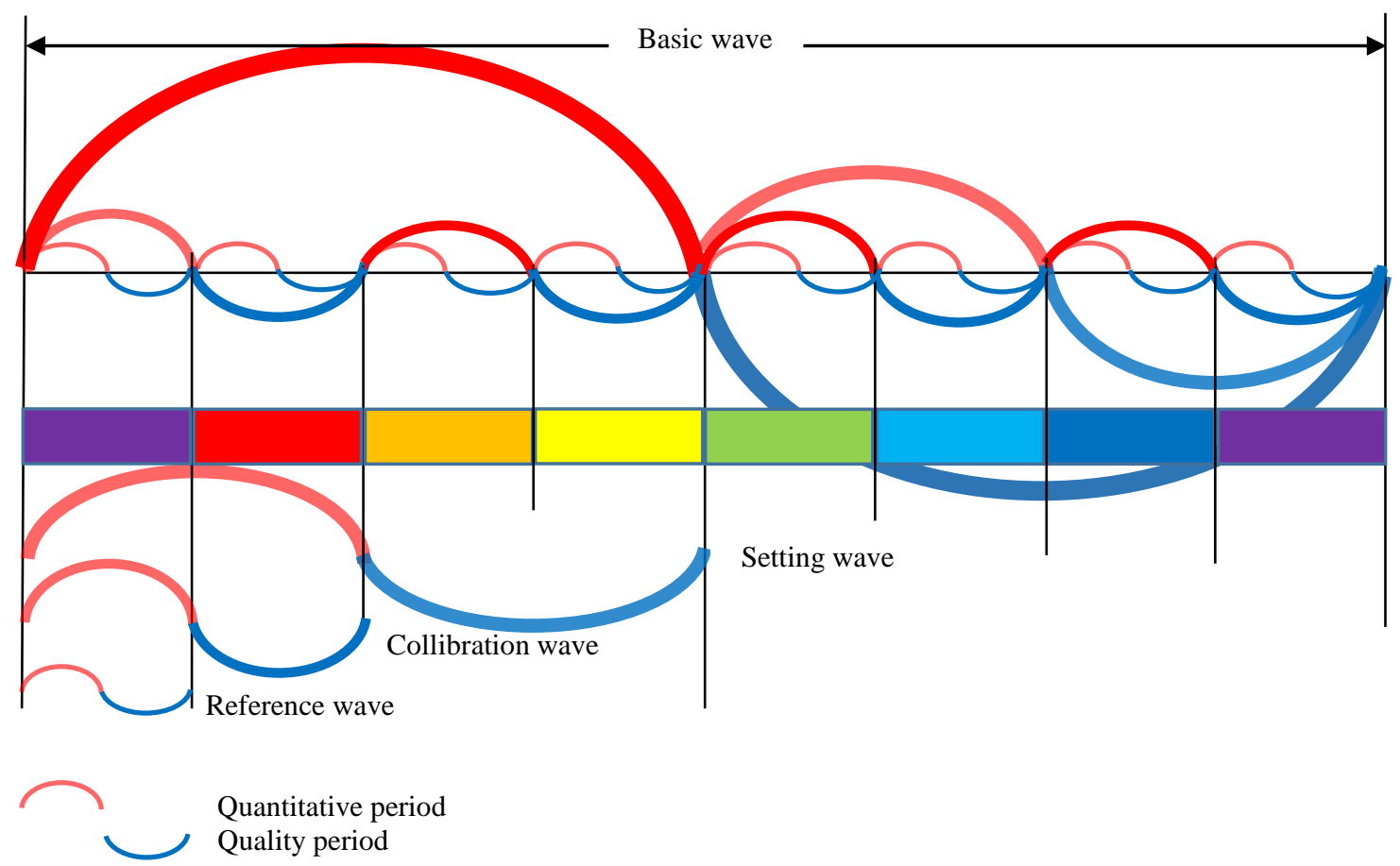

Figure 3. Model of multiplex system development

It is impossible to change the sequence of time periods from the perspective of "temporary (temporal) unit of order". But knowing the duration of the waves, the time coordinates of the beginning and end of the corresponding multiplex wave (hour, date, year, etc.), as well as the indications of its periods, it is possible to interact with the object as correctly as possible. In other words, you can define the time parameters of any process.

However, in the process of development, the state for various reasons may deviate from the norm. This causes a violation of the individual balance between the quantitative and qualitative states. There are two types of balance violation (figure 4). At the first type of imbalance, the general state of the environment comes with an increase in the intensity of the quantitative type information manifestation and a decrease in the intensity of qualitative information type (figure 4.a). And vice versa at the second type of imbalance (figure 4.b).

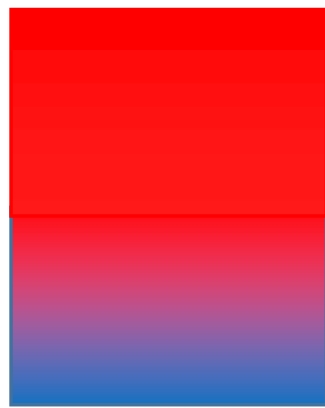

A) Imbalance first kind

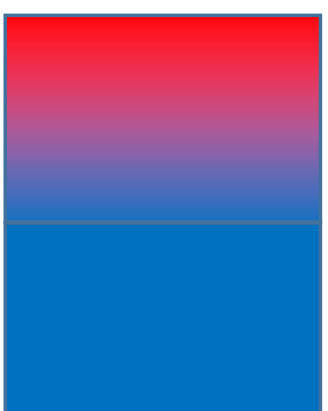

B) Imbalance second kind

Figure.4. kinds of information Imbalance 
Then in certain periods, there will be an overlap of activity due to the period indication and activity due to the type of information imbalance. The periods during which such phenomena occurs are called individual periods of special sensitivity (IPSS). There are four such IPSS in each full conversion period (figure 5). In case of imbalance of type A), the strongest emergence will be in the first qualitative period of the multiplex; in case imbalance B) - in the last qualitative period. The stronger the deviation of the general state is from its individual norm, the stronger is the imbalance.

During periods of special sensitivity, the system must "draw conclusions", i.e., compare the results of real development with the reference. And if the real order of the transformation does not match the reference one, the system, striving for self-preservation, makes a correction of its state. If this does not happen, the system collapses.
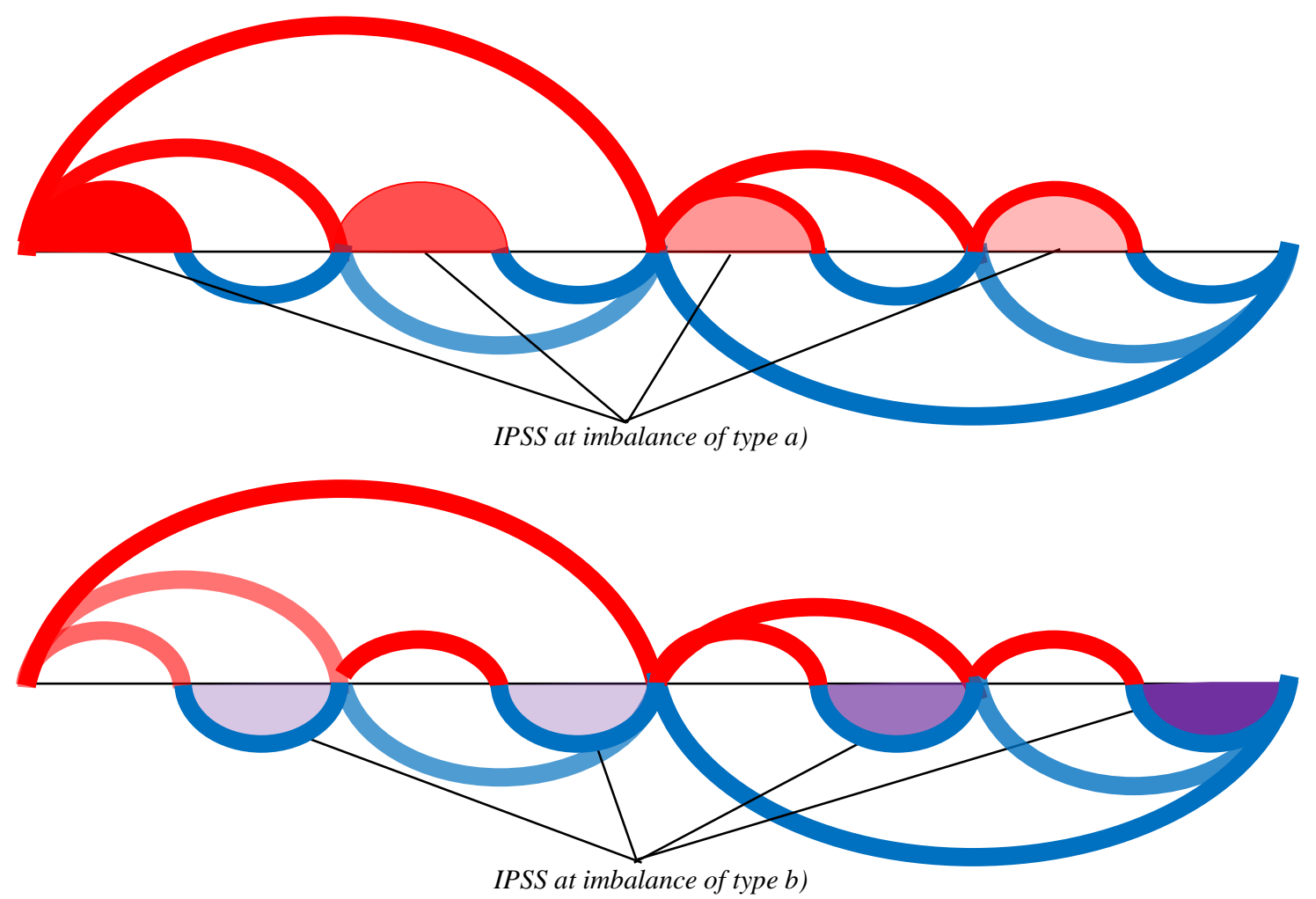

Figure.5. IPSS emergence at imbalance

Thus, according to the system-transdisciplinary paradigm, the development of any fragment is treated as an ordered quantitative and qualitative change in its state. This change encapsulates a strict sequence of time intervals, each of which characterizes the predisposition of the system to certain changes only. These common factors are objective and have a transdisciplinary, universal character.

The foregoing theoretical propositions make it possible to propose a new interpretation of the Crisis Science problems, the observed poly-cyclicality in the development of the world, national economies and individual enterprises, the problems of systems sustainable development. 


\section{EXAMPLES OF SOLUTIONS TO PROBLEMS BASED ON THE SYSTEM-TRANSDISCIPLINARY PARADIGM}

Let us show how the common factors and generalizations described above make it possible to solve the Crisis Science problems, indicated at the beginning of the article. So, the first theoretical problem

\section{- What is the reason for crises emerging?}

As we discussed above, the cause of the crises is explained by the cyclical nature of the economic relations development. Despite the fact that most economists now recognize cyclicality, economic development plans are built on the basis of the continuous economic growth concept. In any case, the author did not have to see at least one long-term plan, which provided for a cyclic development, except for those enterprises and industries where there is an annual, seasonal or daily cycle - agriculture, tourism and so on.

People are elements-fragments of the planetary system, and the development of relations between them is a subject to the temporal law of the planet development. They cannot develop differently.

From the perspective of a system-transdisciplinary paradigm, crises may be interpreted as follows. If being not aware of the seasons' cyclical nature and planning to continuously increase the volume of apple juice production monthly, and, accordingly, buy additional equipment, hire workers, etc., I will have a significant drop in production by spring because the apples will end. I will have to purchase them overseas, costs will grow, then the enterprise will go bankrupt and I will have to fire workers. It means that there will come a crisis in its present understanding - as a negative phenomena, as a result of ignorance of the regularities of the seasonal change.

As a negative phenomena, the economic crisis is a natural reaction on economic relations. This reaction arises in response to planning for continued economic growth and the actions associated with this approach. Planning for continuous growth is like planning a continuous breath or exhalation. It is possible to plan, but it is impossible to inhale or exhale continuously. A person will faint. The economic crisis is the natural reaction of the economy (like a faint) on the wrong people activities. In the words of J. Schumpeter, the crisis is a "cold shower" for the economy, which causes it to be shaken up.

\section{- Is it possible to predict the calendar period for the advent of a crisis?}

The described methodological principles give such a possibility.

For "planetary-dimensional" objects, which is the world economy, crises should match the planet IPSS. Let us calculate the duration of these periods, using the multiplex regularities. Let us determine the base multiplex wave duration for the planet.

We will assume that the planet Earth exists in the ordered environment of the Solar System. Obviously, under these circumstances, the earth year duration of 365 days should be synchronized with a certain reference year of the Solar System. They must be coherent. The lack of such synchronization would lead to a complete loss of the meaning of the planet co-evolutionary development and the outward things. Hence the conclusion - at some point in time, the end of the real earth period and the reference period of the solar system must coincide by odds. Calculations showed that for the first time these years are synchronized on account of the quantitative characteristic in 3.5 real years. These years coincide on account of the qualitative characteristic on the morrow of 7 real years. In other words, 7 terrestrial years are needed in order to complete the synchronization cycle of the real and true (reference) year. Thus, the duration of the reference wave for the "planetary-dimensional" objects can be 3.5 or 7 years. Therefore, being in a certain "time layer", we will observe phenomena that can be referred to:

- cycles of true (reference) periods, the duration of which in the terrestrial years is equal respectively: $1.4 ; 2.8 ; 5.6 ; 11.2 ; 22.4 ; 44.8 ; 89.6 ; 179.2 ; 358.4$ years, etc.

- cycles of real periods, the duration of which is equal respectively: $2 ; 4 ; 8 ; 16 ; 32 ; 64 ; 128 ; 256$, 512 years, etc. 
- synchronization cycles of a real period with a true (reference) period, the duration of which is equal respectively: $3.5 ; 7 ; 14 ; 28 ; 56 ; 112 ; 224 ; 448$ years, etc.

It is easy to verify that the indicated numerical values coincide with the already discovered experimentally cycles of Kitchin, Zhuglyar, Kuznets, Kondratyev, and others. Overlapping each other, coinciding and not coinciding with each other, the totality of these cycles led to the economy polycyclic development and the "blurring" of its picture, especially regarding the average cycles.

Due to our assumptions, the duration of the basic wave for the global economy is 28 years from the cycle phasing array of 3,$5 ; 7 ; 14 ; 28 ; 56 ; 112 ; 224 ; 448 ; 896 ; 1792$ years, etc. Then the duration of the reference wave (crisis) should be equal to 3.5 years. Similar results were obtained by Robert Barro and José Ursua who in the work "Macroeconomic crises since 1870" indicate a figure of 3.5 years (Barro R.J. \& Ursua J.F., 2008).

We determined the type of our planet imbalance as the type a). There are many explanations for this, but it is suffice to mention the inflation in the world economy. Means a quantitative increase in the cash flow. Then periods of special response lasting about 3.5 years on the planet will fall on the corresponding quantitative part of each 7-year period of the multiplex calibration wave. Being aware of the crisis start year, you can calculate all possible calendar periods wherein a crisis could occur.

Using the described common factors, a retrospective analysis of the crises of the world economy was conducted in 1998, and their predicted calendar values were calculated. The calendar dates of the Great Depression of 1929-33 became the starting point for plotting the combining of IPSS and crises in the world economy. Assuming that the duration of the multiplex reference wave is 3.5 years on the timeline, the dates of all corresponding multiplex waves were plotted. ${ }^{3}$ For checking purposes, the data provided by the Soviet researcher L.A. Mendelson, who examined the world crises since 1825, were exposed in the book "Theory and History of Economic Crises and Cycles", (Mendelson L.A., 1964). Studies have shown great representativeness of this calculation method. All crises, beginning from the crisis of 1793 to the present time, fall into a period of special response.

The scope of the article does not allow to place the entire calendar schedule of combining IPSS and crises in the world economy ${ }^{4}$. For figure 6 shows the graph since 1987. Crises of 2000, 2008 and 2016 occurred due to the schedule. Unfortunately, further observations can go beyond the life of the researcher (i.e., myself) but we can assume that the following crises will occur in the period 20242027, 2032-2035 and so on.

\section{- Why every crisis differs from the previous one?}

The development of socio-economic relations represents a succession of phases, just as it happens in a humans - infancy, childhood, adolescence, etc. Therefore, the emergence of deviations has a different nature. Depending on the degree of maturity, the increasing influence of the characteristic benchmark periods on real ones is the cause of the crises dissimilarity. Then the crisis nature and depth depend on whether the information characteristic of the special response period coincides or does not coincide with

the characteristic of the reference period. Besides that, based on theoretical generalizations, the nature of each crisis is determined by the information characteristic of the multiplex development corresponding period. The correlation between the waves of the Kondratyev' cycle, which duration to my calculations is 56 years, is also assumed. However, the confirmation of these hypotheses requires additional research.

\footnotetext{
${ }^{3}$ The results of the analysis and forecasts were described in the book "Space-time factors in the development of economic systems" by Mokiy.M.S. Moscow. Kalita Publishing House. year 2000
} 


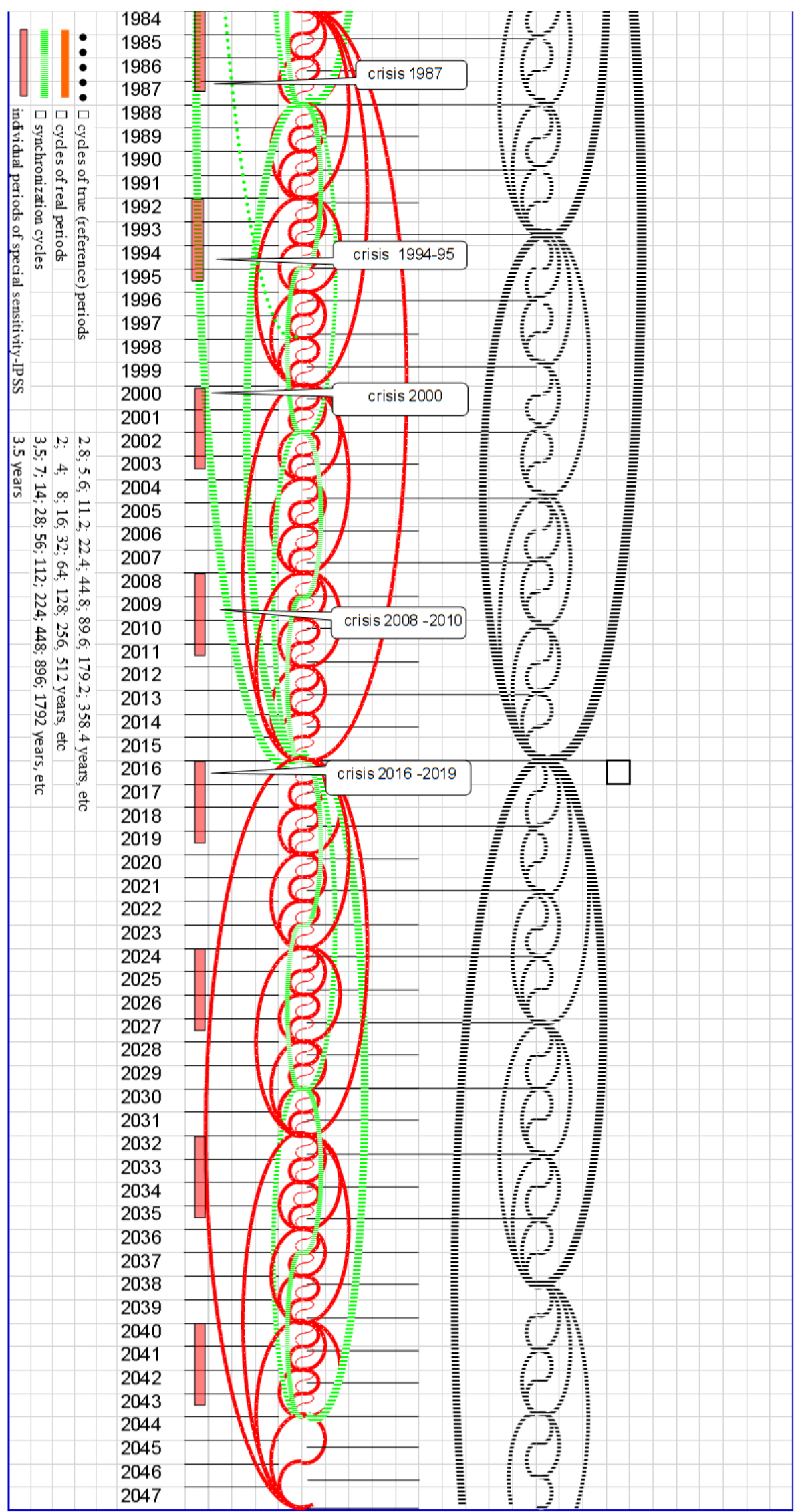

Figure.6. Schedule of combining IPSS and crises in the world economy 
- Why the crisis shows up differently in various countries?

It takes place because:

- countries are found to be at different stages of their development (for example, Japan and Afghanistan);

- countries have different types of imbalances;

- every country has its own temporal common factors of development, which either strengthen or smooth out the impact of the global crisis;

- countries have their own individual rates (for example, Ireland and Indonesia).

These factors determine the specifics of the world crises flowing in different countries from almost imperceptible to deep and strong.

To illustrate it, let us consider the history of the two countries - the USA and the USSR, then Russia. There is a point of view that the socialist planned economy did not suffer from crisis phenomena. Almost a commonplace was the assertion that integrating into the world economy modern Russia is experiencing a clearer and brighter "disease" common to it (the world economy). However, the assertion that the planned socialist economy of the Soviet Union, due to its closed nature, developed without crises is at least incorrect. The cyclical development of the world economy is manifested in all countries. Even a superficial analysis shows that the crisis phenomena in the world economy and the economic reforms in the USSR coincide by times. For instance, the crisis and the Great Depression in 1929-1933 in the United States coincides by times with the crisis in the economy of the USSR. The difference lies in the nature of this crisis manifestation. In the USA, this crisis was a crisis of overproduction, while the USSR at the same time had a famine, the signs of which were already noted in 1928. Bread cards were introduced in many cities already in 1928 . The coincidence by times is observed for other crises.

Thus, the National Bureau of Economic Research of the United States marks 1960-62 as the years of decline in manufacturing outputIt is also characterized by the fact that there is a severe overproduction crisis in the US agriculture. The government spent billions a year on paying farmers bonuses for cutting crop areas. The USSR made first purchase of grain in 1963. In 1962, for the first time since the war, the country increased retail prices for oil by $50 \%$, for meat by $20-40 \%$.

By the late 1960s, the preconditions for a "crisis" of the dollar as the main reserve currency formed. In the early 60's, European leaders reasonably thought that the dollar supply was secured-free. In this regard, there is a well-known story about the ship laden with paper dollars, which France sent to the US, demanding that an equivalent amount of gold be exchanged. Opinions emerged about the need to devalue the dollar, i.e., its depreciation. In 1961, the USSR put in place a monetary reform denomination.

The crisis of overproduction 1980-1983 covered all the industrialized countries of the West. In the USSR, the Central Committee of the CPSU on the strength of the current situation endorsed a special food program in 1982. Food cards were introduced basically everywhere.

The same trend is observed during the crisis of 2008-2011 and 2016. In the USA, prices fall or "freeze" on most goods. In Russia, during these periods, prices are rising, including the interest rate, i.e., the cost of capital. For example, the interest rate in the US on March 3, 2008 was $3.00 \%$ and it dropped to $0.2 \%-0.22 \%$ by the spring of 2009. In Russia, since June 19, 2007, the rate was of $10 \%$, from December 2008 to April 23, 2009 - 13\%. [http://ставка-рефинансирования-цб.pф]. It can be concluded that the crisis manifestation is determined by the type of information imbalance.

\section{- How to prevent crises?}

The article already noted that the crisis is perceived as a negative phenomenon. Are the negative effects of the crisis a natural attribute of economic development? According to the system-transdisciplinary paradigm - no. This is not mandatory at all. 
The Greek word "crisis" means "turning-point". The methodological features provided by the development multiplex enable us to determine the calendar time for performing compensatory measures for both the world economy and for each country separately. This will be the calendar periods corresponding to the multiplex reference waves. In these periods, due to the cyclical nature of their development, economic relations will have a natural predisposition to the events of one kind or another.

Categories of imbalances provide an opportunity to identify the national economy endemic features, which will predetermine the crisis manifestation nature in the country. Undoubtedly, the definition of individual (endemic) crisis manifestation features in each individual country, as well as the content of compensatory measures, requires special studies. However, having received this information, it is possible to develop and conduct preventive measures according to the schedule. Then the crisis period will not be accompanied by negative phenomena, but will be what it has to be - a turning-point.

\section{CONCLUSION}

The article shows how the application of the system-transdisciplinary paradigm can be used to solve the Crisis Science fundamental problems for the world economy. However, the methodological potential of the system-transdisciplinary paradigm allows to set and solve the problems of economic development at different levels in a new way.

That's how the methodological recommendations for planning the development of various business systems based on innovation development schedules, which are built on the basis of a multiplex, were developed (Godin V., Mokiy M., Gureev P, Filonchik V. 2016). It is very difficult to investigate crisis phenomena in firms. However, training managers the basics of this approach will allow them to analyze and build strategic development plans for their companies more reasonably.

One last thing. Most people know such a truism - everything must be done on time. Usage of a systemtransdisciplinary approach to solving problems of managing socio-economic development makes it possible to translate this truism into a methodology. It means that the use of this approach makes it possible to determine very precisely what, how and when to. This makes it possible to transmit a whole series of unpredictable events to predictable ones.

\section{REFERENCES}

Barro Robert J. \& Ursua José F., (2008). «Macroeconomic Crises since 1870» Brookings Papers on Economic Activity, Economic Studies Program, The Brookings Institution, vol. 39(1 (Spring), pages 255-350. p. 49-50

Godin V., Mokiy M., Gureev P, Filonchik V.(2016) Multiplex Waves in the Planning of Innovation Processes in Business System. Handbook of Research on Driving Competitive Advantage through Sustainable, Lean, and Disruptive Innovation. Chapter 4. (pages 86-110). 2016 by IGI Global, Hershey PA, USA. http://www.igi-global.com/book/handbook-research-driving-competitiveadvantage/142171

Mendelson L.A. (1964) "Theory and History of Economic Crises and Cycles". "Mysl" Publishing House. Moscow. Volumes I-III. Pages 1839.

Mokiy V.S., \& Lukyanova T.A. (2017). "Methodology of scientific research: Transdisciplinary approaches and methods". Urite Publishing House, Moscow. Page 163.

Mokiy M.S. 2000. "Space-time factors in the development of economic systems". "Kalita" Publishing House. Moscow. Page 163. 
